\title{
MIDAS
}

Museus e estudos interdisciplinares

$10 \mid 2019$

Varia

\section{Do Carnaval à Luta Livre: Máscaras e Devoções Mexicanas [exposição]}

\section{Maria Manuela Restivo}

\section{(2) OpenEdition}

1 Journals

\section{Edição electrónica}

URL: http://journals.openedition.org/midas/1713

DOI: $10.4000 /$ midas. 1713

ISSN: 2182-9543

\section{Editora:}

Alice Semedo, Paulo Simões Rodrigues, Pedro Casaleiro, Raquel Henriques da Silva, Ana Carvalho

\section{Refêrencia eletrónica}

Maria Manuela Restivo, «Do Carnaval à Luta Livre: Máscaras e Devoções Mexicanas [exposição] », MIDAS [Online], 10 | 2019, posto online no dia 31 maio 2019, consultado no dia 24 setembro 2020. URL : http://journals.openedition.org/midas/1713; DOI : https://doi.org/10.4000/midas.1713

Este documento foi criado de forma automática no dia 24 setembro 2020.

\section{(c) (i) (9)}

Midas is licensed under a Creative Commons Attribution-NonCommercial-ShareAlike 3.0 International License 


\title{
Do Carnaval à Luta Livre: Máscaras e Devoções Mexicanas [exposição]
}

\author{
Maria Manuela Restivo
}

\section{REFERÊNCIA}

Do Carnaval à Luta Livre: Máscaras e Devoções Mexicanas. 2017. Comissariada por Anthony Shelton e co-comissariada por Nicola Levell. Exposição patente no Museu de Lisboa Palácio Pimenta, Portugal, entre 9 de julho a 1 de outubro de 2017.

1 No contexto dos museus e da museologia, um dos assuntos mais prementes dos últimos anos prende-se com a forma de expor objetos provenientes de culturas não ocidentais, nomeadamente daquelas que foram alvo de processos de colonização. Também em Portugal verificamos que essa problemática tem vindo a ser discutida, ainda que o seja quase exclusivamente na esfera das exposições ligadas à arte contemporânea. Já no que diz respeito ao universo dos objetos provenientes das práticas culturais ditas tradicionais - os denominados objetos etnográficos, tradicionais, populares ou vernaculares - notamos que esse debate é praticamente inexistente. De facto, e não obstante a presença de coleções consideráveis em Portugal deste tipo de objetos, existe um desconhecimento generalizado da sua existência, e as exposições em que estes figuram são praticamente nulas.

2 É, por isso, especialmente louvável encontrar, no contexto da programação de "Passado e Presente - Lisboa, Capital Ibero-americana de Cultura 2017", uma exposição dedicada às máscaras mexicanas, que ocorreu no Pavilhão Preto do Museu de Lisboa - Palácio Pimenta entre 9 de julho a 1 de outubro de 2017. Não só esta exposição se destaca pela especificidade das suas peças - os ditos objetos etnográficos, populares ou vernaculares de que acima se falava - e pela sua excecionalidade no panorama da programação do evento (onde predomina a produção artística contemporânea), como vem apresentar uma visão mais condizente com as reflexões teóricas que envolvem a exposição deste tipo de objetos na atualidade. 
Do Carnaval à Luta Livre: Máscaras e Devoções Mexicanas foi uma exposição dedicada fundamentalmente às máscaras mexicanas e aos contextos culturais a estas associados. Comissariada por Anthony Shelton e co-comissariada por Nicola Levell ${ }^{1}$, a exposição apresenta cerca de 250 máscaras mexicanas, acompanhadas de vídeos, fotografias, entre outros objetos e documentos que permitem aceder simultaneamente ao universo estético das máscaras e aos seus contextos de criação e de utilização.

Como atesta o texto da folha de sala, «esta exposição pretende dar espaço e visibilidade às práticas culturais indígenas e populares, revelando visões das histórias entre os impérios Europeus e Americanos». Estamos, assim, perante uma exposição que parte das máscaras para contar um conjunto de histórias, percursos e trajetórias que extravasam o universo restrito do objeto-máscara, para alcançar as relações históricas e culturais nas quais esses objetos originam e circulam.

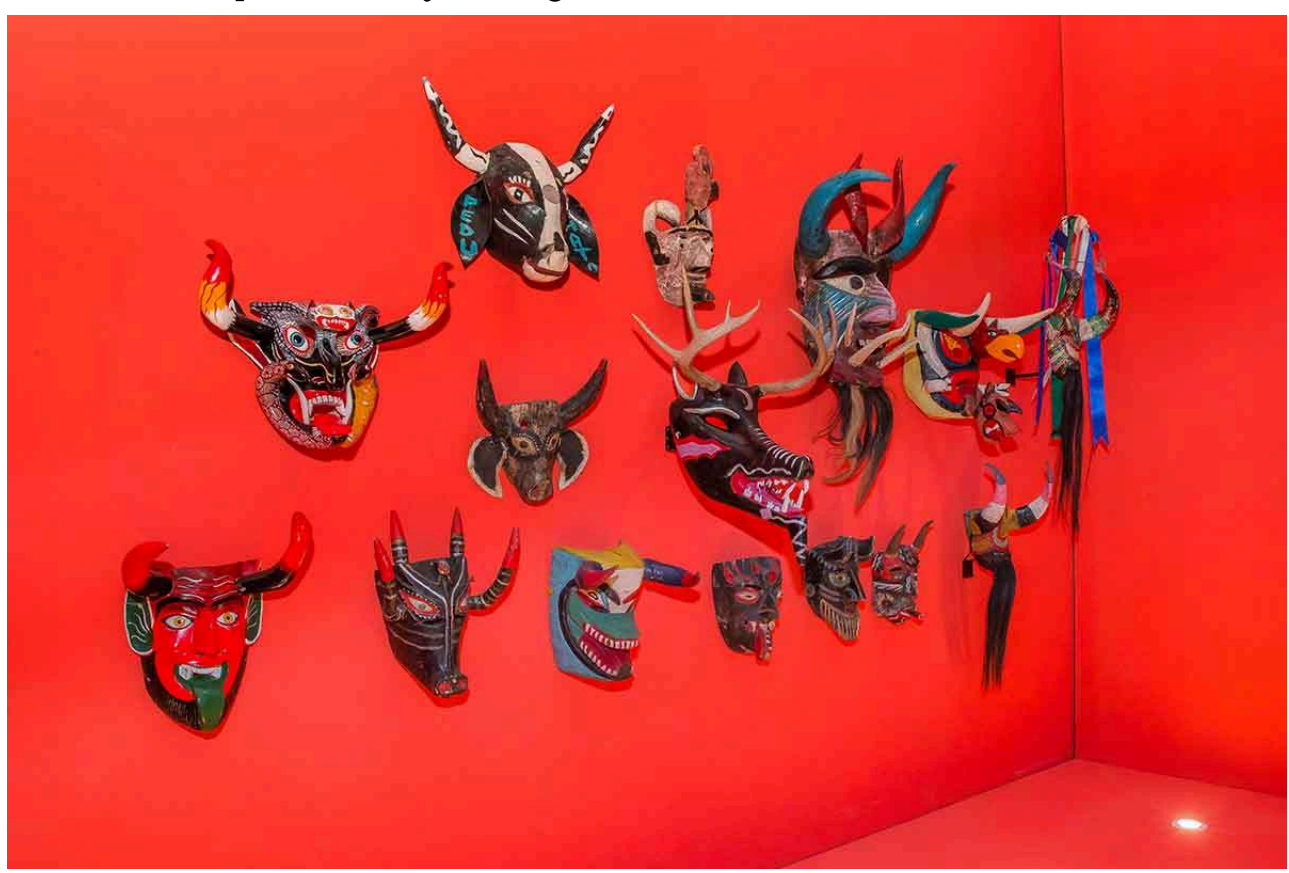

Fig. 1 - Exposição Do Carnaval à Luta Livre: Máscaras e Devoções Mexicanas, 2017, Museu de Lisboa Palácio Pimenta

Fotografia gentilmente cedida pelo jornal aNOTÍCIA.pt @ Aldrabiscas

5 A exposição divide-se fundamentalmente em quatro salas. A primeira, denominada «Mundos Espelhados», apresenta um vasto conjunto de máscaras - expostas numa plataforma original e esteticamente apelativa - acompanhadas de um vídeo que permite a sua contextualização. Trata-se das máscaras dos catrines (dandies europeus) e dos vaqueros/charros (cowboys e fazendeiros) ligadas ao Carnaval dos estados mexicanos de Tlaxcala e Puebla. Estas máscaras são usadas com fatos de cowboy ou com fatos pretos formais, e são, em alguns casos, acompanhados de guarda-chuvas pretos, já que estes eram associados aos europeus e ao poder que lhes imputavam de trazer a chuva.

A segunda sala apresenta o título «Teatro de Memória» e é neste espaço que é possível dar conta da incrível diversidade presente nas máscaras mexicanas e nos contextos em que originam. Das máscaras da morte às máscaras dos monstros da terra, dos demónios aos tigres, as diferentes máscaras podem surgir no Carnaval, na Páscoa, no Corpo de Cristo, no Natal, ou em dias santos, dependendo da sua origem ou significado. 
7 A terceira sala é dedicada aos «Imaginários Mexicanos», destacando os contextos de produção das máscaras nas últimas décadas e a sua relação com o turismo.

A última sala apresenta um outro tipo de máscaras: as máscaras usadas na luta livre, um dos desportos mais populares no México. Se, de um lado da sala nos deparamos com a encenação de um ringue de luta livre (transformado numa plataforma de visionamento de vídeos), no outro encontramos um grupo de fotografias da artista Lourdes Grobet, que permite simultaneamente aceder aos contextos quotidianos dos lutadores e questionar o papel de super-heróis que as personagens assumem "em palco".

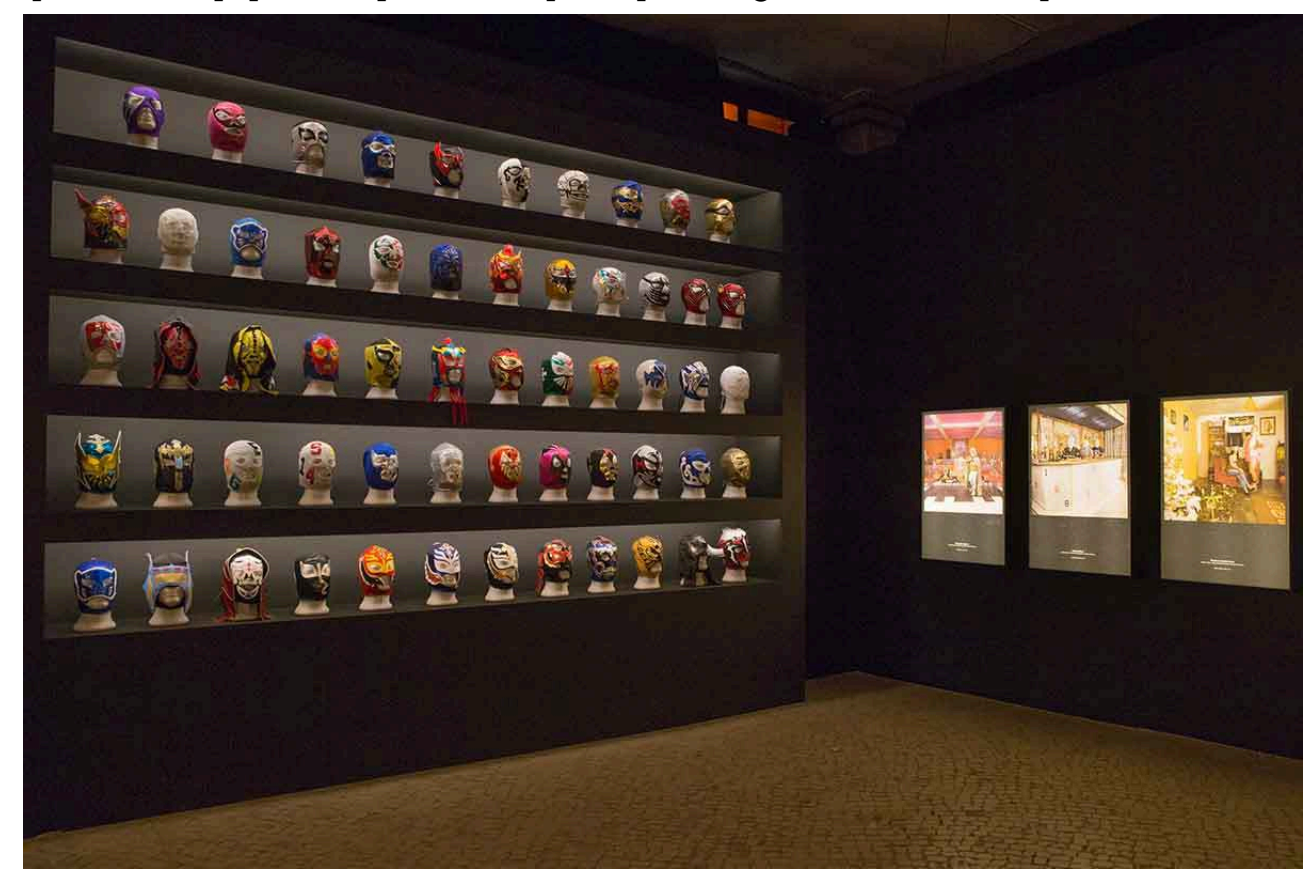

Fig. 2 - Exposição Do Carnaval à Luta Livre: Máscaras e Devoções Mexicanas, 2017, Museu de Lisboa Palácio Pimenta

Fotografia gentilmente cedida pelo jornal aNOTÍCIA.pt (C) Aldrabiscas

Recorrendo a um design de cores vivas e a formatos expositivos originais, a exposição é acompanhada de uma banda sonora (composta pelo som dos diversos vídeos disponíveis para visionamento) que proporciona a imersão nos diferentes contextos de utilização das máscaras. Contudo, mais do que proporcionar uma experiência estética agradável, esta exposição permite refletir sobre as narrativas associadas a este tipo de objetos nos dias de hoje, marcando uma rutura relativamente à forma como estes objetos eram expostos no passado.

10 Em primeiro lugar, o conceito de cultura inerente à exposição é concebido como uma realidade dinâmica e não estática. Ao contrário de um discurso que vigorou durante algum tempo e no qual a diversidade das manifestações culturais desapareceria devido às forças hegemónicas da globalização, esta exposição vem mostrar que as práticas culturais - materiais e imateriais - se vão transformando ao longo dos tempos, dialogando com os acontecimentos históricos e políticos que marcam as sociedades. Esta abordagem é visível em vários pontos da exposição, mas surge com maior acuidade na primeira sala - onde as máscaras locais dialogam diretamente com uma cultura europeia, que nos parece simultaneamente glorificada e satirizada pelas práticas carnavalescas. 
11 Em segundo lugar, nesta exposição questiona-se a ideia do objeto puro e autêntico, que tantas vezes marca o discurso sobre as artes indígenas, "étnicas" ou populares. A terceira sala é exemplar na ilustração desta temática, já que dá conta da produção de máscaras nas décadas de 60, 70 e 80 do século XX, e das ironias históricas inerentes à sua criação e comercialização: alguns modelos que foram divulgados como autênticos (ou seja, produzidos para serem usados nas cerimónias locais) foram criados nos anos 1960 apenas para cumprir as demandas de alguns colecionadores; nos dias de hoje, contudo, não é raro que fotografias de máscaras "inventadas" sirvam de modelo para a construção de máscaras cerimoniais. O facto de diversas destas máscaras estarem presentes na exposição, sublinhando-se o próprio fenómeno inerente à sua criação, questiona desde logo a ideia de objeto autêntico - aquele que seria construído por artistas/artesãos no âmbito das suas práticas tradicionais - substituindo-o por uma visão que encara a produção nativa e popular como um fenómeno capaz de responder a demandas comerciais, sem contudo haver, por um lado, uma perda na qualidade formal do objeto nem, por outro, uma recusa da sua validade antropológica. Não há a ideia de nostalgia pelas práticas culturais do passado, tantas vezes presente na perceção destes objetos, mas antes uma celebração da contingência; não há, por outro lado, divórcio entre o autêntico e o falso, o tradicional e o contemporâneo, mas antes continuidades criativamente construídas pelos autores das máscaras que, é importante referir, aparecem (sempre que possível) identificados pelos nomes próprios e não pelo seu grupo cultural.

Em terceiro lugar, há que destacar nesta exposição uma abordagem que podemos designar por pós-disciplinar. Por um lado, pela inclusão de objetos de diversas "categorias", espaços e temporalidades: objetos indígenas e das culturas populares, de origem urbana, da cultura de massas (as máscaras e os cartazes de luta livre) e da arte contemporânea (as fotografias de Lourdes Grobet). Por outro lado, pela ausência de uma área disciplinar dominante na exposição. De facto, e analisando as exposições que Shelton (2015) tem desenvolvido nos últimos anos, detectamos uma vontade deliberada de abandonar o campo restrito da antropologia (ou pelo menos o eixo clássico "objeto etnográfico - contextos culturais") para operar numa arena na qual se tem constituído a curadoria contemporânea: baseada na construção de relações inusitadas entre diversos espaços, tempos e contextos, transcendendo categorias e disciplinas. No caso desta exposição, é perceptível a relação estabelecida entre as máscaras indígenas e as máscaras de luta livre, no que García Canclini (1989) tem denominado como as continuidades entre o popular-tradicional e as expressões contemporâneas do popular enquanto cultura de massas. Mas vemos também a forma como os objetos das práticas populares dialogam no espaço expositivo com a arte contemporânea, como se tudo fizesse parte do mesmo universo.

13 Para além do contacto com as máscaras mexicanas que esta exposição proporciona, esta é também exemplar na forma como interpela os objetos das práticas culturais indígenas e populares, recusando visões condescendentes (que veem estas artes como inferiores) ou passadistas (que prendem o indígena e o popular ao passado). Olhar estes objetos através das modificações históricas e sociais é, em suma, trazer o mundo contemporâneo para o espaço expositivo. 


\section{BIBLIOGRAFIA}

García Canclini, Néstor. 1989. Culturas Híbridas: Estratégias para Entrar y Salir de la Modernidad. Cidade do México: Editorial Grijalbo.

Shelton, Anthony. 2015. Heaven, Hell and Somewhere in Between. Portuguese Popular Art. Vancouver: MOA/University of British Columbia.

\section{NOTAS}

1. Anthony Shelton e Nicola Levell têm trabalhado na interseção da antropologia, da história da arte e da museologia, realizando diversas investigações e exposições que procuram cruzar estes domínios. Ambos são atualmente professores na Universidade de British Columbia, no Canadá, sendo que Shelton assume também a função de diretor do Museu de Antropologia da mesma Universidade. Shelton defende a prática de uma museologia crítica, baseada na interrogação dos objetos expostos e na construção de narrativas expositivas inovadoras.

\section{AUTORES}

\section{MARIA MANUELA RESTIVO}

Instituto de Sociologia da Universidade do Porto, Portugal, mariamanuelarestivo@gmail.com 